\title{
Relatos de práticas docentes: o discurso do sujeito coletivo desvelando suas contribuições
}

\author{
Teacher practice reports: the collective subject discourse unveiling their contributions
Informes de prácticas de enseñanza: el discurso del sujeto colectivo desvelando sus contribuciones

\author{
LINA MARIA GONÇALVES* \\ GERLANE ROMÃo FONSECA PERRIER** \\ MARIA ELIZABETH BIANCONCINI DE ALMEIDA***
}

\begin{abstract}
RESUMO
As sessões de apresentação de relatos de prática já fazem parte da programação dos Seminários Web Currículo, promovidos pelo Programa de Pós-Graduação em Educação: Currículo da Pontifícia Universidade Católica de São Paulo (PUC-SP). Visando a compreender as contribuições das apresentações de tais práticas, sob a perspectiva dos participantes nas sessões de relatos realizadas na quarta edição desse seminário, em setembro de 2015, foi aplicado um questionário de opinião sobre as contribuições dos relatos apresentados. As respostas às questões subjetivas foram tratadas por meio do Discurso do Sujeito Coletivo (DSC), produzido com o apoio do software Qualiquantisoft; e as ideias-chave foram organizadas em categorias e geraram os DSCs, apresentados e analisados neste artigo; Já as respostas à questão objetiva foram tratadas por meio do software NVivo10. Essas análises revelaram que os relatos contribuíram para ampliar as reflexões docentes e melhorar as práticas com o uso das Tecnologias Digitais de Informação e Comunicação.

Palavras-chave: Prática docente. Tecnologia educacional. Reflexão. Formação docente.
\end{abstract}

\begin{abstract}
The sessions of practice reports presentations are included on Web Curriculum Seminars program, sponsored by the Program of Graduate Studies in Education: Curriculum of the Pontifical Catholic University of São Paulo (PUC-SP). It was applied a questionnaire of opinion about the contributions of the submitted reports in the sessions of accounts held at the fourth edition of this seminar, in September 2015, to understand the contributions of presentations of these practices from the participants perspective. The answers to subjective questions were proceeded through the Collective Subject Discourse (CSD), produced with the support of Qualiquantisoft software. The key ideas were categorized to generate the CSD, presented and analyzed in this article. The answers to the objective question were treated using NVivo10 software. The analysis allowed infer that the reports helped to broaden their thinking and improve practices with the use of Digital Technologies of Information and Communication.
\end{abstract}

Keywords:Teaching practice. Educational technology. Reflection. Teacher training.

\section{RESUMEN}

Las sesiones de práctica de informes presentaciones ya forman parte del programa de Seminarios Web Curriculum, patrocinado por el Programa de Estudios de Graduado en Educación: Curriculum de la Pontificia Universidad Católica de São Paulo (PUC-SP). Se aplicó un cuestionario de opinión sobre las contribuciones de los informes presentados en las sesiones de cuentas realizadas en la cuarta edición de este seminario, en septiembre de 2015, para comprender las aportaciones de las presentaciones de estas prácticas desde la perspectiva de los participantes. Las respuestas a las preguntas subjetivas fueron tratadas a través del Discurso del Sujeto Colectivo (DSC), producido con el apoyo de software de Qualiquantisoft. Las ideas fundamentales fueron actuadas en categorías y generaron el DSC, presentados y analizados en este artículo. Las respuestas a la pregunta objetiva fueron procesada a través de software NVivo10. La análisis nos permitió inferir que los informes ayudaron a ampliar su pensamiento y mejorar las prácticas con el uso de las Tecnologías Digitales de la Información y la Comunicación.

Palabras clave: La práctica docente. Tecnología educativa. La reflexión. La formación del profesorado.

*Doutora em Educação: Currículo, Pontifícia Universidade Católica de São Paulo (PUC-SP). Mestre em Tecnologias da Inteligência e Design Digital pela PUCSP. Professora da Universidade Federal do Tocantins, câmpus de Gurupi - UFT Gpi. E-mail: <lina.mg@uft.edu.br>.

** Professora do Colégio Agrícola Dom Agostinho Ikas - CODAI/UFRPE. Doutoranda do Programa de Pós-Graduação em Educação na Pontifícia Universidade Católica de São Paulo (PUC-SP). Bolsista CNPq. E-mail: <gerlaneperrier@gmail.com>.

*** Doutora em Educação: Currículo. Professora do Programa de Pós-Graduação em Educação: Currículo, Pontifícia Universidade Católica de São Paulo (PUC-SP). E-mail: <bbethalmeida@gmail.com>. 


\section{INTRODUÇÃO}

Cientes da importância do diálogo entre a universidade e as escolas de educação básica, tanto para a aprendizagem dos alunos quanto para o exercício da função social da universidade, as apresentações de relatos de prática, por educadores em atividades nas escolas ou em outras organizações dedicadas à educação, têm constituído a cultura dos Seminários Web Currículo ${ }^{1}$, desde setembro de 2008, ano de sua primeira edição. Assim, nas programações dos seminários, além das sessões de comunicações orais, pôsteres e oficinas, os participantes contam com sessões de relatos de prática, especialmente aquelas que visam à integração das tecnologias digitais ao currículo.

A criação desses espaços se justifica pela relevância da socialização de boas práticas na geração de novos conhecimentos docentes. Assim como Zabalza (2004, p. 137), entende-se que "não é a prática por si mesma que gera conhecimento", mas sim a prática reflexiva, pois permite avançar para estágios cada vez mais elevados no desenvolvimento profissional.

Quais são os conhecimentos teóricos e práticos que orientam o trabalho do professor em sala de aula? Como ele explica e justifica a sua prática pedagógica? Para responder a perguntas dessa natureza, é necessário dar voz ao professor, o que, segundo Woods (1999), significa vê-lo como uma pessoa que tem algo de valor a dizer por direito próprio, ideia que norteia as sessões de relatos de prática.

Ao fazer um relato, escrito e depois oral, o professor escreve para outro leitor e espectador, "por isso, precisa ter em mente, o tempo todo, as seguintes questões: o que dizer e como dizer para outro que não sou eu e que não sabe o que aconteceu?". Assim, as descrições são "acompanhadas de análise e reflexão, de modo que o conteúdo do relato deixe claras as transformações no trabalho realizado com os alunos" (ZELMANOVITS, 2010, p.4).

E, nesse exercício, o professor necessita "voltar, revisar o que se fez, analisar os pontos fortes e fracos" do exercício profissional e progredir com base "em reajustes permanentes. Sem olhar para trás, é impossível seguir em frente" (ZABALZA, 2004, p. 137). Esse exercício reflexivo é fundamental na formação contínua do professor, segundo Nóvoa (1991, 2009); Schön (1983, 1992); Pacheco (1995); Pacheco e Flores (1999); Tardif (2002); Demo (2010); Dias (2013). Outros autores, como Carabetta Júnior (2010) e Benites, Capelasso e Dias (2011), também destacam a importância de o professor

\footnotetext{
${ }^{1}$ Os Seminários Web Currículo, realizados pelo Programa de Pós-Graduação em Educação: Currículo da PUC-SP, têm proporcionado um ambiente para a troca de experiências e o fomento de novas ideias entre professores de diferentes níveis de ensino, pesquisadores no campo do currículo sua integração com as Tecnologias Digitais de Informação e Comunicação.
}

apresentar suas práticas para o domínio dos saberes docentes. "A função de ensinar é socioprática e, por isso, deve ser discutida a própria ação e a dos outros, buscando um domínio sobre o saber" (BENITES; CAPELASSO; DIAS, 2011, p. 73).

Experiências de formação pautadas na tríade "investigação-ação-intervenção", em contextos de formação para a integração curricular das Tecnologias Digitais de Informação e Comunicação (TDICs), mostraram a relevância da reflexão para o alcance dos objetivos de formação. Nesses contextos, o exercício de registrar e socializar as práticas têm servido de "suporte para a reflexão e metarreflexão", tanto para os relatores quanto para os formadores e pesquisadores (ALMEIDA; DIAS; SILVA, 2013, p.259). Esse é um modelo de formação oposto àqueles que estabelecem uma relação linear e hierárquica entre conhecimento científico, acadêmico ou teórico e conhecimento empírico, oriundo da prática.

Concordando com os autores, na quarta edição do Seminário Web Currículo, que no ano de 2015 foi integrado ao XII Encontro de Pesquisadores em Currículo, com o apoio das Pró-Reitorias de Educação Continuada e de Pós-Graduação, foram apresentados 59 relatos de prática pedagógica em ação de ensino e aprendizagem vinculados aos eixos temáticos: "Currículo, Conhecimento, Cultura; Currículo e Avaliação Educacional; Formação de Educadores; Interdisciplinaridade; Novas Tecnologias em Educação; Políticas Públicas e Reformas Educacionais e Curriculares e Pensamento de Paulo Freire" (PUC-SP, 2015).

Ressalta-se que as sessões de relatos de prática pretendem contribuir para a formação dos apresentadores, uma vez que, "embora a experiência seja intransferível, por meio da palavra (oral ou escrita) podemos compartilhá-la com os demais, assim como tomar contato com a experiência do outro" (CARDIA, 2012, p. 25). Mas visam também a auxiliar na formação dos pesquisadores em educação, ao entender, como Tardif (2002, p.238), que a pesquisa universitária sobre a educação fará progressos quando se reconhecer que ela "não produz uma teoria sobre a prática, mas que ela mesma é uma prática referente a atividades (ou seja, ensinar) e a atores (ou seja, os professores) que dispõem de seus próprios saberes e de seus pontos de vista".

De acordo com Wien, Guyevsky e Berdoussis (2011, tradução das autoras do artigo):

A narrativa de prática é uma rota para o ensino de professores, para o desenvolvimento profissional. $\mathrm{O}$ pesquisador deve encorajar os professores a documentar, a reconhecer as suas primeiras tentativas como começos, espaços reservados de ordem, e ter um senso de oportunidade para apoiar os professores em ver que há muito mais com os quais podem envolver para desfrutar, estudar, interpretar, planejar e evoluir. 
Nesse sentido, os membros do grupo de pesquisa Formação de Educadores com Suporte em Meio Digital buscam compreender as contribuições das apresentações dos relatos de prática, sob a perspectiva dos educadores que destas participaram. E este texto apresenta e analisa as opiniões dos respondentes de um questionário de opinião, em relação às contribuições para sua prática pedagógica. Suas opiniões foram tratadas e o "discurso do sujeito coletivo (DSC) ${ }^{2}$ " foi desvelado a partir da abordagem metodológica descrita na próxima seção.

\section{Abordagem METOdológiCA}

Esta investigação adotou a pesquisa qualitativa como princípio epistemológico, visto que os objetos ou sujeitos de pesquisa, nas ciências humanas, "são dotados de liberdade e consciência" (LAVILLE; DIONNE, 1999, p. 32). Dessa forma, para captar a realidade dos fatos humanos, é importante considerar que as pessoas atribuem sentido ao mundo que as cerca.

Lefèvre e Lefèvre (2012) afirmam que o homem, como um atribuidor de sentidos, gera conhecimento nas interações com outros sujeitos com os quais tenha um sistema compartilhado de ideias. Concordando com os autores, buscou-se entender os sentidos atribuídos pelos participantes aos relatos de prática pedagógica em ação de ensino e aprendizagem das sessões de apresentação no IV Seminário Web Currículo e no XII Encontro de Pesquisadores em Currículo.

Desse modo, os relatos de prática, inscritos e aprovados para apresentação no evento, foram organizados em seis sessões, com uma média de dez em cada uma. Ao apresentá-los, os educadores deveriam descrever os objetivos, a justificativa, os desafios enfrentados e as soluções adotadas e, para finalizar, os principais resultados alcançados com sua prática pedagógica, projeto ou experiência vivenciada.

Ao encerrar cada sessão de apresentação, os participantes foram convidados a responder a um questionário de opinião, alcançando 57 respondentes. Este foi constituído por quatro questões sobre as contribuições ou ganhos percebidos pela apresentação e socialização de suas práticas no evento: 1 - "Em sua opinião, quais foram as contribuições dos relatos de prática, apresentados nesta sala, para sua prática?"; 2 - "E quais foram as contribuições para o grupo aqui presente?"; 3 - "Você leva

\footnotetext{
2 O Discurso do Sujeito Coletivo é uma modalidade de apresentação de resultados de pesquisas qualitativas, que tem depoimentos como matéria-prima, sob a forma de um ou de vários discursos-síntese escritos na primeira pessoa do singular, expediente que visa a expressar o pensamento de uma coletividade, como se esta fosse o emissor de um discurso (LEFÈVRE; LEFÈVRE, 2003, p. 70).
}

alguma contribuição para a sua instituição? Qual?”; e, 4 - "Das práticas aqui apresentadas, qual você considera que trouxe mais contribuições?".

Assim, o presente artigo busca compreender a representação social desses sujeitos, que segundo Lefèvre e Lefèvre (2012, p. 7-8) pode ser entendida como "todo tipo de conhecimento gerado no dia a dia na vida das pessoas comuns, um intercâmbio social que permite que as sociedades sejam sistemas simbólicos, sistemas de atribuição de sentidos".

Para a análise das respostas às três primeiras questões foi utilizada a técnica do DSC, em que os depoimentos coletados foram metodologicamente tratados por meio do Qualiquantisoft ${ }^{3}$, com o objetivo de obter o pensamento coletivo. Foram identificadas as expressõeschave em cada resposta, e estas foram agrupadas em cinco categorias, conforme semelhança ou complementaridade.

Já na questão de número 4, que solicitou a indicação de qual relato foi mais significativo para o sujeito, portanto apresentando respostas pontuais, formadas em geral por uma única palavra ou expressão título do relato, foi utilizado o software NVivo $10^{4}$ para a construção da nuvem de palavras.

Os resultados estão apresentados e analisados a seguir, sob a forma de discursos-síntese, escritos na primeira pessoa do singular, expressando o pensamento dos participantes das sessões de relatos de prática no IV Seminário Web Currículo e no XII Encontro de Pesquisadores em Currículo.

\section{RESUltados E DiscuSSÃo}

A seguir, são apresentados os DSCs correspondentes às questões 1,2 e 3 , organizados nas categorias: Troca de Experiências, Uso de Tecnologias, Novas Práticas, Reflexão e Formação de Professores.

Os sujeitos participantes das seis sessões de relatos de prática pedagógica em ação de ensino e aprendizagem destacaram a relevância da troca de experiências. Tais seções ocorreram simultaneamente, em salas diferentes. Após tratamento das ideias-chave arroladas à categoria, esta foi expressa nos discursos do sujeito coletivo, mostrados no Quadro 1.

\footnotetext{
3 O Qualiquantisoft é um programa desenvolvido com base na teoria do Discurso do Sujeito Coletivo, que segundo Lefèvre e Lefèvre (2012) permite o processamento de dados para a análise de recortes discursivos através da criação de um banco de dados que filtra os discursos em estratos e os compara.

${ }^{4}$ Nvivo10 é um software de apoio à análise de dados em pesquisa qualitativa produzido pela QSR International, que permite a organização e a análise de entrevistas, discussões de grupos, questionários, áudios, vídeos, páginas da internet e artigos de periódicos científicos.
} 
Quadro 1 - Discursos do Sujeito Coletivo arrolados na categoria Troca de Experiências

\begin{tabular}{|c|c|c|}
\hline $\begin{array}{l}1 \text { - Em sua opinião, quais foram as } \\
\text { contribuições dos relatos de prática, } \\
\text { apresentados nesta sala, para sua } \\
\text { prática? }\end{array}$ & $\begin{array}{l}2 \text { - E quais foram as contribuições } \\
\text { para o grupo aqui presente? }\end{array}$ & $\begin{array}{l}3 \text { - Você leva alguma contribuição } \\
\text { para a sua instituição? Qual? }\end{array}$ \\
\hline $\begin{array}{l}\text { Para mim, os relatos de prática } \\
\text { foram excelentes, pois foi possível } \\
\text { conhecer outras realidades, ampliar } \\
\text { ideias, conceitos e aprendizagens e o } \\
\text { conhecimento de novas tecnologias } \\
\text { e formas de ensinar para envolver } \\
\text { ainda mais os alunos. Assisti a relatos } \\
\text { do que os outros pesquisadores } \\
\text { vêm desenvolvendo, representando } \\
\text { fonte de intercâmbio de saberes e } \\
\text { ampliação das possibilidades de } \\
\text { parcerias. Conheci o que vem sendo } \\
\text { feito nas escolas e pude contar o que } \\
\text { estamos fazendo. Percebi que o desejo } \\
\text { de aprender está presente em todas } \\
\text { as esferas. Momentos de troca de } \\
\text { experiências sempre são relevantes. } \\
\text { Estes contribuíram positivamente } \\
\text { não só para a minha prática, pois } \\
\text { compartilharei com meus colegas } \\
\text { o que presenciei aqui. Além disso, } \\
\text { procuro adequar cada aprendizagem à } \\
\text { minha realidade. Foi muito rico, mas o } \\
\text { tempo foi pouquíssimo. }\end{array}$ & $\begin{array}{l}\text { Por meio da socialização das práticas } \\
\text { desenvolvidas com tecnologia, } \\
\text { colaborei com conquistas dos meus } \\
\text { alunos e pude transmitir para o grupo } \\
\text { experiências e contatos para ampliação } \\
\text { e complementação de nossas } \\
\text { pesquisas e atividades profissionais. } \\
\text { Por abordar várias temáticas, de } \\
\text { diferentes contextos e eixos, a troca } \\
\text { de experiências contribuiu para que o } \\
\text { outro aprendesse de forma muito mais } \\
\text { proveitosa, com a riqueza cultural e } \\
\text { com a forma como cada profissional } \\
\text { a desenvolve, contando suas práticas. } \\
\text { Houve diversidade de temas e troca } \\
\text { de experiências e de realidades } \\
\text { diferentes em diversas áreas, tais como } \\
\text { saúde, educação, tecnologia, novos } \\
\text { recursos e outras ferramentas, além } \\
\text { das que foram passadas. A interação } \\
\text { e o conhecimento de novos pares } \\
\text { que pesquisam sobre o currículo, } \\
\text { web currículo e práticas usadas nas } \\
\text { diversas escolas, em relação ao uso de } \\
\text { tecnologias, trazem muitas ideias, pois } \\
\text { conhecer outros trabalhos e ver outras } \\
\text { perspectivas permite envolver todos, } \\
\text { desde a educação infantil até o } \\
\text { ensino médio. }\end{array}$ & $\begin{array}{l}\text { Sim. Trocas de experiências e } \\
\text { conhecimentos sobre educação, } \\
\text { diversidade, tecnologias, histórias de } \\
\text { inclusão, os projetos Luz na minha } \\
\text { vida e de ação docente em parceria. } \\
\text { Relatos que vieram acrescentar } \\
\text { na prática de sala de aula. Enfim, } \\
\text { levo para minha instituição novos } \\
\text { conceitos, novas ideias, experiências } \\
\text { compartilhadas, conhecimento em } \\
\text { relação às tecnologias existentes. } \\
\text { Experiências muito boas, porém pouco } \\
\text { científicas e sem aprofundamento nas } \\
\text { questões problematizadoras. }\end{array}$ \\
\hline
\end{tabular}

(Fonte: Elaborado pelas autoras com o apoio do software Qualiquantisoft a partir das respostas às questões 1, 2 e 3)

Esses DSCs explicitaram a relevância do confronto entre os saberes produzidos pela experiência coletiva dos professores. O destaque dado aos momentos de "conhecer o que vem sendo feito nas escolas e contar o que estamos fazendo" mostra a compreensão de que é por meio "das relações com os pares [...] que os saberes experienciais adquirem certa objetividade". Ao participar de uma sessão de relato de práticas, o sujeito percebeu que a vontade ou o desejo que sente de aprender e melhorar a prática pedagógica é compartilhada por outros sujeitos e instituições. E isso gerou motivação para multiplicar os relatos com os colegas de trabalho, fazendo as adequações ou recontextualização destas para sua realidade. Ao expor suas experiências aos pares e ouvir as deles, ampliam-se as ideias, os conceitos e as aprendizagens. Os saberes são sistematizados, transformando-se "num discurso da experiência capaz de informar ou de formar outros docentes e fornecer uma resposta aos seus problemas" (TARDIF, 2002, p. 52).

Os sujeitos também destacaram o uso de tecnologias digitais presentes nos relatos, tanto em relação aos usos pedagógicos e metodologias para esse uso quanto às ferramentas que passaram a conhecer a partir das experiências compartilhadas por seus pares, como mostra o Quadro 2. 
Quadro 2. Discursos do Sujeito Coletivo arrolados na categoria Uso de Tecnologias

\begin{tabular}{|c|c|c|}
\hline $\begin{array}{l}1 \text { - Em sua opinião, quais foram as } \\
\text { contribuições dos relatos de prática, } \\
\text { apresentados nesta sala, para sua } \\
\text { prática? }\end{array}$ & $\begin{array}{l}2 \text { - E quais foram as contribuições } \\
\text { para o grupo aqui presente? }\end{array}$ & $\begin{array}{l}3 \text { - Você leva alguma contribuição } \\
\text { para a sua instituição? Qual? }\end{array}$ \\
\hline $\begin{array}{l}\text { As questões apresentadas de uso } \\
\text { das TDICs, com uma diversidade de } \\
\text { intenções e reais possibilidades de } \\
\text { transposição didática, permitiram-me } \\
\text { visualizar o uso das tecnologias de } \\
\text { forma contextualizada e não as ver } \\
\text { como barreira. Vivenciei novas ideias } \\
\text { e discussões para as práticas de sala } \\
\text { de aula e como utilizar ferramentas } \\
\text { tecnológicas para trabalhar conteúdos } \\
\text { curriculares, de diversas disciplinas. } \\
\text { Percebi a necessidade de buscar a } \\
\text { aproximação das tecnologias com } \\
\text { as práticas pedagógicas e para o } \\
\text { desenvolvimento do meu trabalho. } \\
\text { Conheci como estão sendo utilizados, } \\
\text { na escola, novos e interessantes } \\
\text { softwares, tais como o Stopmotion e } \\
\text { o Appers, além de possíveis formas } \\
\text { de abordagem: narrativa, leitura } \\
\text { compartilhada, coautoria. }\end{array}$ & $\begin{array}{l}\text { As contribuições foram sobre as } \\
\text { diversas formas de uso de tecnologias. } \\
\text { Os alunos mostram mais interesse } \\
\text { curricular quando integrados a uma } \\
\text { tecnologia, que seja o celular, redes } \\
\text { sociais ou ambientes virtuais. }\end{array}$ & $\begin{array}{l}\text { Muitas. Levo a contribuição } \\
\text { de conhecer outras realidades, } \\
\text { outros tipos de trabalhos e outras } \\
\text { possibilidades de uso de algumas } \\
\text { ferramentas e aplicações, tal como a } \\
\text { utilização de Appers no processo de } \\
\text { construção do conhecimento, além } \\
\text { do uso de aplicativos para a mesma } \\
\text { finalidade. Levo, ainda, a possibilidade } \\
\text { de utilizar recursos e materiais que } \\
\text { não requerem gasto financeiro, o que } \\
\text { permitirá colocar a tecnologia mais } \\
\text { constantemente em minhas aulas, } \\
\text { assim como tornar o aluno mais } \\
\text { protagonizante. }\end{array}$ \\
\hline
\end{tabular}

(Fonte: Elaborado pelas autoras com o apoio do software Qualiquantisoft a partir das respostas às questões 1, 2 e 3)

Observa-se nesses DSCs que participar das apresentações de relatos de prática com o uso das TDICs possibilitou desmistificar as tecnologias. Muitas vezes, estas são consideradas de difícil uso e, algumas vezes, como barreiras para o trabalho do professor. O sujeito percebeu novas possibilidades, novas formas de atuação, nas quais o uso das tecnologias pode melhorar a prática docente, destacando-se as experiências de uso das tecnologias para compartilhamento de leituras e produções, em um processo de coautoria. Ressaltando, ainda, a possibilidade de construção das narrativas digitais, que são defendidas por Almeida e Valente (2012, p. 63) como um exercício que "envolve o saber, a identidade e a racionalidade sobre como as pessoas constroem o conhecimento do mundo ao seu redor, a compreensão de si mesmo e a interlocução com outras pessoas".

Corroborando a visão desses sujeitos, Bergamaschi (2003, p. 143), constata que, com a expansão das tecnologias digitais, "mais do que em qualquer outra época é exigido hoje do professor o exercício do papel de educador". E explica que usa a palavra 'exercício' no sentido literal, qual seja o de "aprender fazendo, exercitando, experimentando $\mathrm{e}$, principalmente, querendo ser".
De fato, o acesso às novas ferramentas artefatos, interfaces, aplicativos e linguagens tecnológicas, associado à reflexão sobre possíveis formas de utilização, tem sido característica dos relatos. Isso demonstra a potencialidade que esses recursos, disponíveis e a serem disponibilizados, podem acrescentar ao processo educacional. Além disso, as TDICs facilitam a criação de uma rede de conhecimentos e favorecem, também, a troca de informações e experiências e a compreensão crítica da realidade (ALMEIDA, 2008).

Como afirma Clandinin (1985, p.363), o discurso e a reconstrução da experiência pelos professores podem revelar os seus conhecimentos práticos, um conhecimento "formado e baseado na narrativa da experiência". E a apropriação das TDICs também é um tipo de conhecimento prático e particular de conhecimento produzido pelos professores na prática e para a prática, mediada pela reflexão, assim como ocorre com a construção gradativa de suas experiências pessoais e sua visão de mundo (CLANDININ, 1985; ELBAZ, 1981; SCHÖN, 1983).

Segundo os sujeitos, os relatos de prática ampliaram sua visão sobre as possibilidades de uso das tecnologias para novas práticas em sala de aula, conforme os DSCs arrolados na categoria Novas Práticas, apresentado no Quadro 3. 
Quadro 3. Discursos do Sujeito Coletivo arrolados na categoria Novas Práticas

\begin{tabular}{|c|c|c|}
\hline $\begin{array}{l}1 \text { - Em sua opinião, quais foram as } \\
\text { contribuições dos relatos de prática, } \\
\text { apresentados nesta sala, para sua } \\
\text { prática? }\end{array}$ & $\begin{array}{l}2 \text { - E quais foram as contribuições } \\
\text { para o grupo aqui presente? }\end{array}$ & $\begin{array}{l}3 \text { - Você leva alguma contribuição } \\
\text { para a sua instituição? Qual? }\end{array}$ \\
\hline $\begin{array}{l}\text { Os relatos trouxeram práticas } \\
\text { inovadoras na educação sobre } \\
\text { áreas que ainda não conhecia } \\
\text { profundamente. É muito interessante } \\
\text { saber as práticas usadas nas diversas } \\
\text { escolas: novas ideias, novos } \\
\text { aplicativos, novas possibilidades } \\
\text { metodológicas, atividades práticas } \\
\text { e concretas, propostas vivenciadas } \\
\text { e novos conceitos, como trabalhar a } \\
\text { tecnologia na sala de aula, mediação e } \\
\text { estratégias para facilitar o processo de } \\
\text { ensino e aprendizagem. Percebi como } \\
\text { os conteúdos curriculares podem ser } \\
\text { adaptados e apresentados ao nosso } \\
\text { alunado e a importância da tecnologia } \\
\text { na prática pedagógica, para dinamizar } \\
\text { o fazer pedagógico. Alguns temas } \\
\text { tratados ampliaram minha visão das } \\
\text { possibilidades, tais como a mudança } \\
\text { do currículo em uma visão de } \\
\text { educação híbrida e de multimodalidade } \\
\text { nos mais diversos níveis de ensino. } \\
\text { Contribuíram para minha prática } \\
\text { pedagógica, trazendo luz para a } \\
\text { organização da unidade que atuo, para } \\
\text { novas pesquisas e para a descoberta } \\
\text { de novos mundos. Realmente, aprendi } \\
\text { muito e colocarei em prática. }\end{array}$ & $\begin{array}{l}\text { Conhecer outras possibilidades e ações } \\
\text { pedagógicas que estão dando certo, } \\
\text { onde destaco o ensino híbrido nos } \\
\text { mais diversos níveis de ensino, sua } \\
\text { concepção e conceito, além de suas } \\
\text { implicações sobre o currículo para } \\
\text { o século XXI. Foram apresentadas } \\
\text { várias temáticas diferentes, tais como } \\
\text { plataforma EaD, projetos tecnológicos, } \\
\text { WhatsApp na educação, formação na } \\
\text { área de arte contemporânea, arte do } \\
\text { corpo na educação especial, formação } \\
\text { em rede municipal em tecnologias } \\
\text { educacionais. Todas as contribuições } \\
\text { foram significativas. }\end{array}$ & $\begin{array}{l}\text { Ótimas ideias e práticas docentes para } \\
\text { pensarmos em diferentes propostas e } \\
\text { estratégias para o currículo com uso } \\
\text { das tecnologias no contexto escolar, } \\
\text { tais como a validação do Facebook } \\
\text { como plataforma interativa com fins } \\
\text { pedagógicos; a facilidade de trabalho } \\
\text { com os apps na escola; o Edmodo; } \\
\text { as narrativas digitais; o trabalho com } \\
\text { música e a formação em EaD; } \\
\text { a experiência apresentada pela escola } \\
\text { do RJ sobre educação musical; o } \\
\text { relato sobre robótica em Recife; as } \\
\text { conferências por Skype com outras } \\
\text { escolas; o Stopbulling. Temas e } \\
\text { sugestões a serem discutidos com os } \\
\text { pares e adequados a nossa realidade, } \\
\text { que despertaram o interesse por } \\
\text { conhecer mais sobre metodologias de } \\
\text { formação de professores e mediação } \\
\text { com os alunos; reorganização do } \\
\text { tempo e espaços; ensino híbrido, } \\
\text { suscitando a vontade de iniciar a } \\
\text { discussão com o grupo para } \\
\text { implantá-lo. }\end{array}$ \\
\hline
\end{tabular}

(Fonte: Elaborado pelas autoras com o apoio do software Qualiquantisoft a partir das respostas às questões 1, 2 e 3)

Esses DSCs destacam as novidades que as sessões de relato de prática lhe proporcionaram: ideias, conceitos, aplicativos, possibilidades metodológicas, adaptações de conteúdos, atividades práticas e concretas, propostas para uso das tecnologias na sala de aula, assim como de mediação para o ensino e para a aprendizagem. O olhar desse sujeito está voltado para as novidades e ele ressalta que há algo de novo nos currículos, ressaltando o modelo híbrido. Reafirma que os relatos trouxeram "luz" para sua visão sobre as novas formas de organização curricular e abriram-lhe perspectivas que levará para sua instituição.

Esse "otimismo pedagógico" do sujeito que viu e ouviu algo "novo", aprendeu e afirma que colocará em prática mostra a importância dos relatos de prática. Constata-se, entretanto, que as novidades apresentadas representam o que deu certo, mas "o que não deu muito certo, as dúvidas, as dificuldades e as hipóteses que o professor formula para explicar o que se passou são tão importantes quanto as conquistas e, como elas, carecem de menção e reflexão" (ZELMANOVITS, 2010, p.8). Ao "olhar para trás", o profissional reflete sobre a prática em questão, e essa reflexão "pode ser considerada uma estratégia importante para a docência, visto que permite encontrar caminhos para o aprimoramento da prática e descobrir acertos e erros do trabalho educacional para construir novos rumos de atuação" (CARABETTA JÚNIOR, 2010, p. 582). Ao apresentar suas práticas, o educador passa a um nível superior de compreensão, ou seja, refletir e falar sobre determinada prática pode funcionar como ponto de referência para o professor sobre o que é aprender e como ensinar. 
Nessa mesma linha, as categorias reflexão e formação de professores emergiram das ideias-chave dos discursos dos sujeitos. Assim, os DSCs decorrentes dessas categorias, mostrados nos Quadros 4 e 5, destacaram a contribuição dos relatos de prática para a formação e para a reflexão docente (TARDIF, 2002; ZABALZA, 2004).

Nos DSCs decorrentes da categoria Reflexão, certificase que novas aprendizagens foram potencializadas pelos momentos de troca e reflexão.
O sujeito declara que, durante as sessões em que participou, gostou, aprendeu, ampliou conhecimentos, motivou-se a aprender mais e, principalmente, que refletiu sobre sua prática pedagógica, repensando, inclusive, o planejamento para o próximo ano. As atitudes desse sujeito constituem objetivos a serem cultivados na práxis pedagógica, pois, como afirma Dewey, novas aprendizagens demandam que o sujeito

Quadro 4. Discursos do Sujeito Coletivo arrolados na categoria Reflexão

\begin{tabular}{|c|c|c|}
\hline $\begin{array}{l}1 \text { - Em sua opinião, quais foram as } \\
\text { contribuições dos relatos de prática, } \\
\text { apresentados nesta sala, para sua } \\
\text { prática? }\end{array}$ & $\begin{array}{l}2 \text { - E quais foram as contribuições } \\
\text { para o grupo aqui presente? }\end{array}$ & $\begin{array}{l}3 \text { - Você leva alguma contribuição } \\
\text { para a sua instituição? Qual? }\end{array}$ \\
\hline $\begin{array}{l}\text { Gostei bastante dos relatos de } \\
\text { diferentes experiências, de lugares } \\
\text { diversos, de várias áreas de } \\
\text { conhecimento. Aprendi muito e } \\
\text { estou motivada a aprender ainda } \\
\text { mais, pesquisar sobre educação } \\
\text { intercultural e refletir cada vez mais } \\
\text { sobre meu papel como educadora. Os } \\
\text { relatos colaboraram principalmente } \\
\text { de maneira interdisciplinar para } \\
\text { repensar as metodologias da educação. } \\
\text { Considerei muito reflexivos, pois } \\
\text { trazem diferentes problemáticas, } \\
\text { reflexões sobre possibilidades para } \\
\text { novas ações educativas importantes } \\
\text { para toda a comunidade escolar, tais } \\
\text { como registro, processo, memória, } \\
\text { ciência, avaliação, reflexões da prática } \\
\text { e resultados. Com as tecnologias, os } \\
\text { problemas continuam os mesmos, } \\
\text { porém com soluções diversas. } \\
\text { A troca de experiências e a } \\
\text { possibilidade de novas abordagens em } \\
\text { sala de aula permitem reflexões acerca } \\
\text { das novas ideias e da necessidade } \\
\text { de sairmos dos padrões tradicionais } \\
\text { de ensino, incorporando o uso } \\
\text { transparente da tecnologia. Pude } \\
\text { repensar minha prática pedagógica e } \\
\text { ampliar conhecimentos sobre o uso } \\
\text { consciente da tecnologia em sala de } \\
\text { aula, sobre a inserção das TDICs } \\
\text { na educação de forma integrada ao } \\
\text { currículo. Descobri práticas que me } \\
\text { fizeram repensar no planejamento } \\
\text { para } 2016 .\end{array}$ & $\begin{array}{l}\text { Os relatos estimularam o debate e } \\
\text { trouxeram sugestões para melhorar } \\
\text { nossas pesquisas. Cada relato trouxe } \\
\text { algo novo, uma nova perspectiva, } \\
\text { cruzamentos das práticas e quebra de } \\
\text { paradigmas, limites e possibilidades, } \\
\text { compartilhamento. A principal } \\
\text { contribuição foi entender as diferentes } \\
\text { formas e públicos onde o ensino/ } \\
\text { aprendizagem é aperfeiçoado, } \\
\text { possibilitando repensar a educação na } \\
\text { atualidade/cultura digital, em diferentes } \\
\text { contextos e visões, e em diferentes } \\
\text { realidades. A percepção do quanto a } \\
\text { cultura fomentou as construções de } \\
\text { conhecimentos e as relações sociais } \\
\text { mostra uma visão concreta do aspecto } \\
\text { construtivista na prática educacional, } \\
\text { em que as práticas apresentadas podem } \\
\text { ser adaptadas e usadas. Através da } \\
\text { dialogicidade, podemos experimentar a } \\
\text { liberdade para sermos autônomos e levar } \\
\text { os nossos alunos a descobrirem-se seres } \\
\text { livres e emancipados. }\end{array}$ & $\begin{array}{l}\text { Eu já tinha uma ideia de projeto } \\
\text { de extensão na escola sobre uma } \\
\text { aprendizagem livre, mas, após } \\
\text { repensar e refletir sobre utilização } \\
\text { da tecnologia na prática pedagógica } \\
\text { e sobre o papel da escola na cultura } \\
\text { digital, levo um novo olhar sobre } \\
\text { o uso de tecnologia e elaboração } \\
\text { da tecnologia, com um desejo } \\
\text { grande de me dedicar à educação } \\
\text { livre, intercultural, construcionista, } \\
\text { tecnológica, que são novos desafios e } \\
\text { ideias para refletirmos com os alunos. }\end{array}$ \\
\hline
\end{tabular}


esteja absolutamente interessado em determinado objeto, em determinada causa, atira-se-lhe, como dizemos, 'de coração' ou de todo o coração. A importância dessa atitude ou disposição é geralmente reconhecida em questões práticas e morais. No desenvolvimento intelectual, é, entretanto, igualmente grande (DEWEY, 1933, p. 40).

Ao tratar de práticas pedagógicas de integração das tecnologias ao currículo escolar, tais atitudes ativas (ou proativas) dos docentes podem representar o diferencial para a promoção de web currículos, pois, como explica Almeida (2014, s.p.), web currículo é muito mais do que a informatização do ensino, pois "ele representa a integração curricular abrangendo a tecnologia e toda sua multiplicidade de linguagens".

Ao ser convidado a responder às perguntas de maneira escrita, o professor busca em suas lembranças as contribuições decorrentes das trocas de experiências que julga mais importantes, aquelas que podem ser consideradas como emergência de web currículo, ou seja, em que ocorreu, de fato, o imbricamento das TDICs no desenvolvimento do currículo, em que houve integração, interferências e transformações, tanto no currículo quanto nas tecnologias utilizadas nas atividades pedagógicas, e, sobretudo, em que os alunos se apropriaram dessas tecnologias e as utilizaram para aprender (ALMEIDA, 2010; ALMEIDA; ALVES; LEMOS, 2014; ALMEIDA; VALENTE, 2015).
Todavia, ao tentar enumerar e descrever tais experiências, o professor exercita a reflexão, que justifica a importância atribuída de como e por que elas influenciaram a ponto de serem lembradas e de se querer disseminá-las, levando-as às suas instituições.

De acordo com Zabalza (1994, p. 95):

Ao narrar a sua experiência recente, o professor não só a constrói linguisticamente, como também a reconstrói ao nível do discurso prático e da atividade profissional (a descrição vê-se continuamente excedida por abordagens reflexivas sobre os porquês e as estruturas da racionalidade e justificam que fundamentam os factos narrados). Quer dizer, a narração implica reflexão.

Assim, considerando que reflexão e formação docente estão intrinsecamente relacionadas, apresenta-se, no Quadro 5, o DSC Formação de Professores, para continuar a análise concomitante com o DSC Reflexão.

Os DSCs produzidos a partir da categoria Formação de Professores mostram concordância com Cardia (2012) quando afirma que a experiência, embora intransferível, pode ser compartilhada com os demais, e que esse exercício é relevante para a formação de ambos.

Esses DSCs destacam a visão positiva das ações dos professores, creditando os avanços à paixão, ao prazer, à dedicação e ao profissionalismo destes para inovar-se, assim como para provocar inovações em suas práticas

Quadro 5. Discursos do Sujeito Coletivo arrolados na categoria Formação de Professores

\begin{tabular}{|c|c|c|}
\hline $\begin{array}{l}1 \text { - Em sua opinião, quais foram as } \\
\text { contribuições dos relatos de prática, } \\
\text { apresentados nesta sala, para sua } \\
\text { prática? }\end{array}$ & $\begin{array}{l}2 \text { - E quais foram as contribuições } \\
\text { para o grupo aqui presente? }\end{array}$ & $\begin{array}{l}3 \text { - Você leva alguma contribuição } \\
\text { para a sua instituição? Qual? }\end{array}$ \\
\hline $\begin{array}{l}\text { Os relatos de prática me marcaram } \\
\text { bastante sobre o esforço e empenho } \\
\text { que os professores brasileiros fazem } \\
\text { para inovar na educação. Trouxeram- } \\
\text { me contribuições interessantes } \\
\text { relacionadas à formação de professores } \\
\text { e projetos pedagógicos, além da } \\
\text { importância da tecnologia educacional } \\
\text { na formação do docente; do papel } \\
\text { da tecnologia como ferramenta para } \\
\text { projetos interdisciplinares. Fiquei } \\
\text { muito feliz por poder vivenciar a } \\
\text { dedicação e o profissionalismo (a } \\
\text { paixão e o prazer) desses professores } \\
\text { de trabalharem em suas escolas e com } \\
\text { seus alunos. }\end{array}$ & $\begin{array}{l}\text { Trouxeram inúmeras contribuições } \\
\text { para o enriquecimento profissional } \\
\text { e pessoal, preenchendo lacunas que } \\
\text { existem dentro do currículo e na } \\
\text { formação de professores. }\end{array}$ & $\begin{array}{l}\text { A necessidade do uso da tecnologia, } \\
\text { como contribuição indispensável para } \\
\text { a aproximação do sujeito com a cultura } \\
\text { contemporânea. }\end{array}$ \\
\hline
\end{tabular}

(Fonte: Elaborado pelas autoras com o apoio do software Qualiquantisoft, a partir das respostas às questões 1, 2 e 3) 
na escola. Enfatizam, ainda, o papel das tecnologias no desenvolvimento de projetos interdisciplinares. Esses professores inspiraram os interlocutores com seu esforço em inovar a educação pela mudança de suas práticas, mostrando-se como sujeitos capazes de captar as alternativas postas pelas TDICs e revelando que "deixar para trás legados históricos tornados obsoletos é habilidade de rara acuidade, própria de gente que mantém a mente aberta, apesar de todo e qualquer êxito" (DEMO, 2010, p. 865).

Formação docente e capacidade reflexiva devem caminhar juntas, pois esta se concretiza a partir do desenvolvimento daquela, ou seja, a reflexão deve ser o objetivo primeiro da formação docente. Portanto, como explica Carlos Marcelo García (2005, p. 153), a meta de qualquer estratégia provocadora da reflexão "consiste em desenvolver nos professores competências metacognitivas que lhes permitam conhecer, analisar, avaliar e questionar a sua própria prática docente, assim como os substratos éticos e de valor a ela subjacentes".

O professor reflexivo e pesquisador é aquele que busca questões relativas à sua prática com o objetivo de aperfeiçoá-la, assim ele vai da teoria para a prática e de volta à teoria, mas de forma ressignificada. Esse processo é denominado metacognição (PACHECO; FLORES, 1999), pois o professor começa refletindo sobre a prática, mas, em um processo ascendente, passa a refletir não somente sobre sua prática, como também sobre seu próprio processo de refletir sobre a prática. Assim, o professor reflexivo vai modificando suas formas de agir e de pensar, num processo contínuo de autoformação.

Nesse sentido, teoria e prática, reflexão e formação se confundem, tornando-se duas faces de um mesmo processo. O professor que ensina é, também, um sujeito aprendente, visto que "aprender a ensinar é um processo que surge da articulação entre teoria e prática, mas fortemente dependente de um contexto prático". O conhecer se dá na práxis, na "reflexão e ação verdadeiramente transformadora da realidade, fonte de conhecimento reflexivo e criação" (FREIRE, 2005, p. 106). Ou, nas palavras de Vázquez (1990), é por meio de elevada consciência filosófica, que a práxis pode alcançar um nível criador. Ou seja, todo conhecimento adquirido sobre os alunos, escola, contexto, conteúdos e sobre si próprio não pode ser adquirido pela teoria, mas, sim, "por meio da reflexão da prática" (BENITES; CAPELASSO; DIAS, 2011, p. 71).

Pérez Gómez (1997) também aponta a importância da reflexão na formação do professor. Para esse autor, os modelos de formação docente, que estabelecem uma relação linear e hierárquica entre o conhecimento científico e as suas aplicações práticas, estão ultrapassados e precisam ser substituídos por um modelo de formação reflexiva. Isso porque, sendo lineares, criam, também, uma relação linear entre tarefas de ensino e processos de aprendizagem.

Mas a formação reflexiva, dentro da profissão (NÓVOA, 1991), pode ser fator de orientação de ações e condutas do professor na sala de aula. Ou, como explica Lima (2007), a formação do professor deve relacionar-se ao contexto e às práticas pedagógicas e de ensino.

Essa formação reflexiva, relacionada ao contexto e às práticas, fundamental para professores, também o é para pesquisadores em educação, pois

\begin{abstract}
com o relato do professor é possível conhecer o que para ele é observável e o que não é, o que prioriza e o que não menciona, ao que atribui valor e ao que não atribui; enfim, nas linhas e entrelinhas, o leitor espera perceber a capacidade de observação e reflexão do professor sobre os processos implicados em sua ação (ZELMANOVITS, 2010, p. 8).
\end{abstract}

Em relação à escolha do relato de prática que trouxe mais contribuições, dentre as apresentadas, não foi possível identificar uma, como se observa no mapa de nuvens, a seguir.

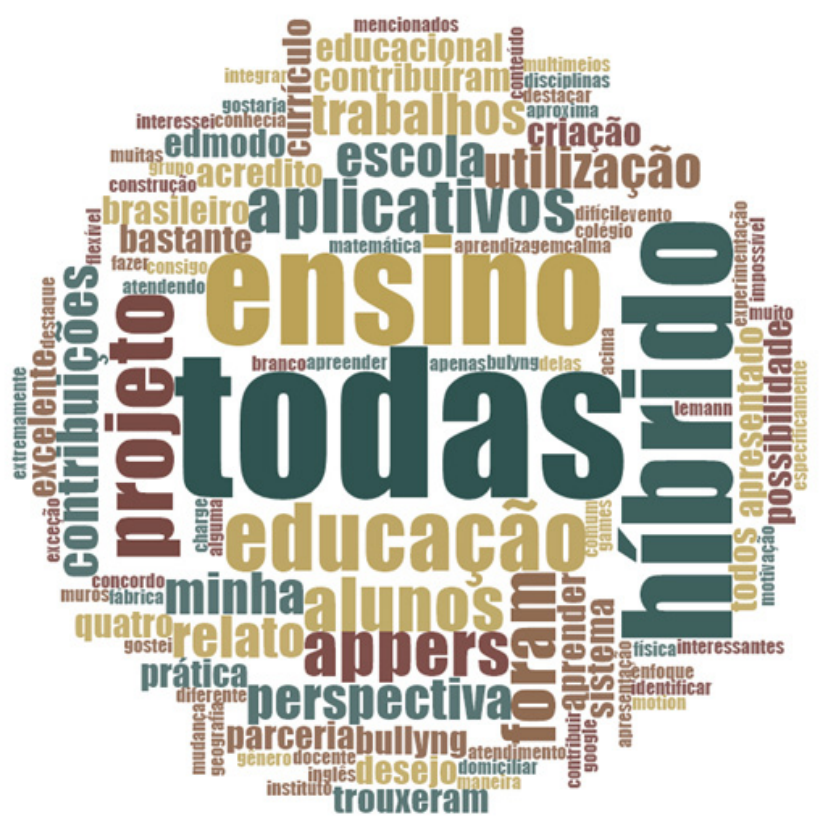

Figura 1. Mapa de nuvens sobre o relato de prática que trouxe mais contribuições aos participantes

(Fonte: Elaborado pelas autoras com apoio do software NVivo 10 a partir das respostas à questão 4)

No centro da nuvem evidencia-se a palavra TODAS, revelando que os sujeitos tiveram dificuldades em escolher um relato, antes consideraram que todas as práticas apresentadas contribuíram para sua aprendizagem 
e reflexão sobre o uso das tecnologias digitais. Ou, talvez, naquele momento, não tenham conseguido destacar uma apresentação mais significativa, visto que "para compreender o resultado da prática é necessário desentranhar sua verdade e utilidade" (PALAZÓN MAYORAL, 2007, p.4). Esse dado permite constatar que, assim como a equipe de organização dos Seminários Web Currículo, a visão dos participantes do evento é que as sessões de relatos de prática devem ser replicadas nas próximas edições e, na medida do possível, em horários diferentes, permitindo a participação dos sujeitos em mais de uma sessão.

Concordando com Tardif (2002), a pesquisa universitária sobre a educação precisa reconhecer a importância da prática de ensinar e do exercício reflexivo sobre esta. Relatar e ouvir as apresentações dos professores é fundamental para relator e ouvintes. O processo de elaboração e apresentação dos relatos, além de proporcionar aos interlocutores se reconhecerem como autores de sua própria formação, aponta a importância da prática, não como mera prática, mas como espaço privilegiado para a reflexão teórico-prática de relatores e espectadores. Inevitavelmente, a formação de educadores deve partir e retornar à práxis, pois "a reflexão crítica sobre a prática se torna uma exigência da relação Teoria/Prática sem a qual a teoria pode ir virando blábláblá e a prática, ativismo" (FREIRE, 2003, p. 22). Nessa visão, momentos de relatos de prática, como os ocorridos nos Seminários Web Currículo, permitem a interação entre professores e pesquisadores e favorecem a formação de ambos.

\section{CONSIDERAÇÕES FINAIS}

Este estudo revela que a proposição ao professor que registre e apresente suas práticas pode gerar nele momentos de reflexão, bem como a seus pares e, ainda, que essas podem ser instrumentos de pesquisa educacional. Cumpre ressaltar que a prática relatada pode tomar proporções relevantes, à medida que promove sua própria depuração, bem como das práticas de outros docentes, como consequência da socialização e reflexão sobre as experiências relatadas. O que implica novas concepções para o planejamento das ações futuras em uma espiral ascendente de desenvolvimento da prática docente.

$\mathrm{O}$ relato de práticas pedagógicas com o uso de tecnologias integradas ao currículo tem se mostrado a cada nova edição do Web Currículo um exercício que vem contribuindo para a formação dos participantes. E, na visão destes, para a melhoria do processo de ensino e aprendizagem, conforme pode ser observado nos Discursos do Sujeito Coletivo, apresentados e analisados neste trabalho. Como princípio epistemológico, só o fato de os sujeitos se apropriarem desses espaços e compartilharem suas experiências com seus pares já pode ser considerado um avanço, no sentido de que a apresentação provoca a reflexão e a ampliação da percepção do que fazer com a tecnologia, que está presente de forma ubíqua na sociedade, e de forma relevante no espaço escolar.

Por fim, acrescenta-se que a abertura de espaço para os relatos de prática, na programação dos Seminários de Web Currículo, tem se mostrado como uma excelente oportunidade de disseminação de experiências. Assim, sugere-se que seja estimulada a continuidade do processo de socialização por meio da criação de grupos de discussão vinculados tanto a programas de Pós-Graduação em Educação, às licenciaturas, quanto às escolas ou a outros contextos envolvidos com a educação, cujas atividades constituam-se em uma rede de conhecimento, tornando-se um fórum permanente para novos relatos e discussões das práticas em Web Currículo.

\section{REFERÊNCIAS}

ALMEIDA, Maria Elizabeth Bianconcini de. Web currículo: a convergência digital é o futuro. Entrevista [17 abril 2014]. Associação Brasileira de Editores de Livros Escolares. Entrevista concedida a Ivani Cardoso. Disponível em: $<$ http:// www.abrelivros.org.br/home/index.php/noticia\%20s/5597web-curriculo-a-convergencia-digital-e-o-futuro>. Acesso em: 03 mar. 2016.

ALMEIDA, Maria Elizabeth Bianconcini de. Integração de currículo e tecnologias: a emergência de web currículo. Anais do XV Endipe - Encontro Nacional de Didática e Prática de Ensino. Belo Horizonte: UFMG, 2010.

ALMEIDA, Maria Elizabeth Bianconcini de. Tecnologia na escola: criação de redes de conhecimentos, 2008. Disponível em: <http://webeduc.mec.gov.br/midiaseducacao/material/ introdutorio/popups/m1_e2_pop_TecnologiaNaEscola.html $>$. Acesso em: 13 mar. 2016.

ALMEIDA, Maria Elizabeth Bianconcini de; ALVES, Robson Medeiros; LEMOS, Silvana Donadio Vilela (Org.). Web currículo: aprendizagem, pesquisa e conhecimento com o uso de tecnologias digitais. Rio de Janeiro/RJ: Letra Capital, 2014.

ALMEIDA, Maria Elizabeth Bianconcini de; DIAS, Paulo; SILVA, Bento Duarte da (Org.). Cenários de inovação para a educação na sociedade digital. São Paulo: Loyola, 2013.

ALMEIDA, Maria Elizabeth Bianconcini de; VALENTE, José Armando. Núcleo de base 2: Integração entre Currículo e Tecnologias Digitais de Informação e Comunicação: material didático. Curso de Especialização em Educação na Cultura Digital. Universidade Federal de Santa Catarina, 2015. Disponível em: <http://catalogo.educacaonaculturadigital.mec. gov.br/site>. Acesso em: 20 abr. 2015.

ALMEIDA, Maria Elizabeth Bianconcini de; VALENTE, José Armando. Integração currículo e tecnologias e a produção de narrativas digitais. Currículo sem Fronteiras, v. 12, n. 3, p. 57-82, set./dez. 2012. Disponível em: <http://www. curriculosemfronteiras.org/vol12iss3articles/almeida-valente. pdf>. Acesso em: 02 nov. 2015. 
BENITES, Mikelli Cristina Pacito; CAPELASSO, Rosângela Regina Marcicano; DIAS, Carmen Lúcia. O ser e estar da ação docente: uma reflexão necessária. In: Colloquium Humanarum, Presidente Prudente, v. 8, n. 2, p. 69-77, jul./ dez. 2011. Disponível em: <http://revistas.unoeste.br/revistas/ ojs/index.php/ch/article/viewFile/427/640>. Acesso em: 17 out. 2015. doi:10.5747/ch.2011.v08.n2.h112

BERGAMASCHI, Maria Aparecida. Será o professor de história um educador? Revista História: debates e tendências. Passo Fundo, RS, v. 4, n. 1, p. 142-147, 2003.

CLANDININ, D. Jean. Personal practical knowledge: a study of teachers' classroom images. In: Curriculum Inquiry, v. 15, n. 4, p. 361-385, 1985.

CARABETTA JÚNIOR, Valter. Rever, pensar e (re)significar: a importância da reflexão sobre a prática na profissão docente. Revista Brasileira de Educação Médica, v. 34, n. 4, p. 580-586, 2010. Disponível em: <http://www. scielo.br/pdf/rbem/v34n4/v34n4a14.pdf>. Acesso em: 17 out. 2015.

CARDIA, Maria Tereza Antonia. Narrar a experiência. Tirando de letra. In: Na Ponta do Lápis, ano VIII, n. 20, p.24-27, 2012. Disponível em: <https://www.escrevendoofuturo.org.br/ EscrevendoFuturo/arquivos/2186/narrar_a_experiencia.pdf $>$. Acesso em: 17 out. 2015.

DEMO, Pedro. Rupturas urgentes na educação. Ensaio: aval. pol. públ. educ., Rio de Janeiro, v. 18, n. 69, p. 861-872, out./ dez. 2010. Disponível em: <http://www.scielo.br/pdf/ensaio/ v18n69/v18n69a11.pdf>. Acesso em: 9 nov. 2014.

DEWEY, John. Como pensamos. Como se relaciona o pensamento reflexivo com o processo educativo: uma reexposição. São Paulo: Editora Nacional, 1933.

DIAS, Paulo. Aprendizagem colaborativa e comunidades de inovação. In: ALMEIDA, Maria Elizabeth Bianconcini de; DIAS, Paulo; SILVA, Bento Duarte da (Org.). Cenários de inovação para a educação na sociedade digital. São Paulo: Loyola, 2013. p. 13-20.

ELBAZ, Freema. The teacher's "practical knowledge": report of a case study. Curriculum Inquiry, v. 11, n. 1, p.43-71, 1981

FREIRE, Paulo. Pedagogia do oprimido. 45. ed. Rio de Janeiro: Paz e Terra, 2005.

FREIRE, Paulo. Pedagogia da autonomia: saberes necessários à prática educativa. 26. ed. Rio de Janeiro: Paz e Terra, 2003.

GARCÍA, Carlos Marcelo. Formação de professores: para uma mudança educativa. Porto: Porto, 2005.

LAVILLE, Christian; DIONNE, Jean. A construção do saber: manual de metodologia da pesquisa em ciências humanas. Belo Horizonte: Artmed/UFMG, 1999.

LEFÈVRE, Fernando; LEFÈVRE, Ana Maria Cavalcanti. Curso teórico prático de introdução ao discurso do sujeito coletivo e ao software QualiQuantiSoft. São Paulo: Instituto de Pesquisa do Discurso do Sujeito Coletivo (IpDsc), 2012. Disponível em: <https://scholar.google.com/scholar_lookup?t itle $=+$ Curso + te $\% \mathrm{C} 3 \%$ B 3 rico + pr $\%$ C3 $\%$ A 1 tico + de + introdu $\%$ $\mathrm{C} 3 \% \mathrm{~A} 7 \% \mathrm{C} 3 \% \mathrm{~A} 3 \mathrm{o}+\mathrm{ao}+$ discurso + do + sujeito + coletivo $+\mathrm{e}+\mathrm{ao}+$ Software + Qualiquantisoft\&author $=$ LEFEVRE + F\&author $=$ LE
FEVRE + A. + M. + C\&publication_year=2011>. Acesso em: 10 set. 2015.

LEFÈVRE, Fernando; LEFÈVRE, Ana Maria Cavalcanti. A utilização da metodologia do discurso do sujeito coletivo na avaliação qualitativa dos cursos de especialização Capacitação e Desenvolvimento de Recursos Humanos em Saúde - CADRHU. In: Saúde e Sociedade, São Paulo, v. 12, n. 2, p. 68-75, jul.dez. 2003. Disponível em: <http://www.scielo.br/pdf/sausoc/ v12n2/07.pdf>. Acesso em: 20 mar. 2016.

LIMA, Marcos Henrique Meireles. O professor, o pesquisador e o professor-pesquisador. 2007. Disponível em: $<$ http://www. amigosdolivro.com.br/lermais_materias.php?cd_materias= 3754>. Acesso em: 17 mar. $201 \overline{6}$.

NÓVOA, Antonio. Professores: imagens do futuro presente. Lisboa/Portugal: Educa, 2009. Disponível em: <http://www. etepb.com.br/arq_news/2012texto_professores_imagens_do_ futuro_presente.pdf $>$. Acesso em: 10 jan. 2015.

NÓVOA, Antonio. Formação de professores e profissão docente, 1991. Disponível em: <http://core.ac.uk/download/ pdf/12424596.pdf>. Acesso em: 20 abr. 2014.

PACHECO, José Augusto. O pensamento e a ação do professor. Porto: Porto Editora, 1995.

PACHECO, José Augusto; FLORES, Maria Assunção. Formação e avaliação de professores. Porto: Porto Editora, 1999.

PALAZÓN MAYORAL, María Rosa. A filosofia da práxis segundo Adolfo Sánchez Vázquez. In: BORON, Atilio A.; AMADEO, Javier; GONZALEZ, Sabrina. A teoria marxista hoje. Problemas e perspectivas, 2007. ISBN 978987118367-8. Disponível em: <http://bibliotecavirtual.clacso.org.ar/ar/libros/ campus/marxispt/cap.13.doc>. Acesso em: 10 jan. 2016.

PÉREZ GÓMEZ, Angel. O pensamento prático do professor: a formação do professor como profissional reflexivo. In: NÓVOA, Antonio (Org.). Os professores e sua formação. Lisboa: Publicações Dom Quixote, 1997.

PUC-SP. IV Seminário Web Currículo e XII Encontro de Pesquisadores em Currículo. Pontifícia Universidade Católica de São Paulo, 2015. Disponível em: <http://www.pucsp.br/ webcurriculo/trabalhos-aprovados.html >. Acesso em: 18 out. 2015.

SCHÖN, Donald Alan. Formar professores como profissionais reflexivos. In: NÓVOA, Antonio (Org.). Os professores e sua formação. Lisboa/Portugal: Dom Quixote, 1992.

SCHÖN, Donald Alan. The reflective practitioner: how professionals think in action. New York: Basic Books, 1983.

TARDIF, Maurice. Saberes docentes e formação profissional. 7. ed. Rio de Janeiro, Petrópolis: Vozes, 2002.

VÁZQUEZ, Adolfo Sánchez. Filosofia da práxis. Trad. de Luiz Fernando Cardoso. 4. ed. Rio de Janeiro: Paz e Terra, 1990.

WIEN, Carol Anne; GUYEVSKY, Victoria; BERDOUSSIS, Noula. Learning to document in Reggio-inspired education. Early Childhood and Practice, v. 13, n. 2, 2011. Disponível em: <http://ecrp.uiuc.edu/v13n2/wien.html>. Acesso em: 01 mar. 2016. 
WOODS, Peter. Investigar a arte de ensinar. Porto: Porto Editora, 1999.

ZABALZA, Miguel A. Diários de aula: um instrumento de pesquisa e desenvolvimento profissional. Porto Alegre: Artmed, 2004.

ZABALZA, Miguel A. Diários de aula: contributo para o estudo dos dilemas práticos dos professores. Porto: Porto Editora, 1994.
ZELMANOVITS, Cris. Relatar a prática: como e por quê? Olimpíada de Língua Portuguesa: escrevendo o futuro, out. 2010. Disponível em: <https://www.escrevendoofuturo.org. br/EscrevendoFuturo/arquivos/2188/relatar_a_pratica.pdf $>$. Acesso em: 17 out. 2015.

Recebido em 07-04-2016. Aprovado em 04-04-2017. 